\title{
Mapping of Urban Features of Nnewi Metropolis Using High Resolution Satellite Image and Support Vector Machine Classifier
}

\author{
Innocent Chukwukalo Ezeomedo ${ }^{1}$ \& Joel Izuchukwu Igbokwe ${ }^{2}$
}

1. Department of Environmental Management, Chukwuemeka Odumegwu Ojukwu University (COOU), Uli Campus, Nigeria.

2. Department of Surveying \& Geoinformatics, Nnamdi Azikiwe University (NUA), Awka, Nigeria.

\begin{abstract}
When maps and master plan of an area are available, they will definitely guide in the urban development, especially as a working document for enforcing planning laws by both government and the private urban developers. However, such basic geospatial information is reasonably lacking in this study area and sequel to this, the researcher aims at Mapping of Urban Features (Natural and Man-Made), which includes the Vegetation, wetlands/water bodies, buildings/pavement, open/bare surfaces and farm lands captured in GeoEye-1, High Resolution Satellite Image (HRSI) of 2016 using Support Vector Machine Classifier (SVMC) with a view of developing a reliable urban land use and land cover map of the area, which will serve as a base map for land-use planning and monitoring for a variety of end-users. The objectives include: to identify and extract features/regions of interest (ROIs) in a subset HRSI of the study area, to perform supervised classification using SVM in ENVI Software. The methodology used include Image acquisition, Image enhancement, Image Sub-setting, Image masking, Extraction of Regions of Interests (ROIs) and its separability index analysis, supervised classification using SVMC, Post-processing Accuracy Assessment, and Preparation of maps. Environment for Visualizing Image (ENVI 5.1) incorporated with Interactive Data Language (IDL 8.3) software was used for image processing, masking, spatial data analysis and image classification. Meanwhile, Esri ArcGIS 10.2 was employed for database development and production of thematic maps. Microsoft Excel and word was used for statistical analysis and result presentation. The result of image classification using SVMC, Radial Basis Function (BRF) default kernel in ENVI 5.1 indicates that Nnewi-North L.G.A is having $13.52 \%$ of Built-up Areas, $24.23 \%$ of Vegetation, $22.05 \%$ of Water bodies, Farm lands is equal to $39.40 \%$ and open/bare surface is $0.81 \%$ and result of image classification was validated using Error Matrix and Kappa Coefficient which results revealed that (SVMC overall Accuracy $=98.07 \%$ and Kappa Coefficient $=0.97$. The result revealed that 'Support Vector Machine Classifier' is robust in extracting urban landscape from HRSI, especially Built-up areas and open/bare for every Remote Sensing Analysis. The research recommends that it is imperative to check for 'ROIs index separability' before using it for classification, also there is need for periodic urban LULC analysis to guide stakeholders in Planning, Monitoring, and Management of Urban Areas..
\end{abstract}

Keywords: Support Vector Machine Classifier, Extraction of Regions of Interests (ROIs), ROIs separability index analysis, High Resolution Satellite Image (HRSI), Urban Landuse and Landcover.

DOI: $10.7176 / \mathrm{JEES} / 9-6-11$

Publication date:June $30^{\text {th }} 2019$

\section{Introduction}

Remote sensing is the science of obtaining information about an object through the analysis of data acquired by a sensor that is not in contact with the object (Jensen, 2007). Earth observation is based on the premise that information is available from the electromagnetic energy field arising from the earth's surface or atmosphere and in particular from the spatial, spectral and temporal variations in that field (Levin, 1999; Kramer, 2002; Sabino, 2005). Through this, the environment can be better monitored, modelled, and consequently, better policy decisions made. Support Vector Machines (SVMs) are a group of relatively novel statistical learning algorithms that have not been extensive exploited in the geospatial science community, (Shi and Yang, 2012). Their basic idea is to construct separating hyperplanes between classes in feature space through the use of support vectors which are lying at the edges of class domains. SVM seek the optimal hyperplane that can separate classes from each other with the maximum margin (Vapnik, 1995). Several commonly used kernel functions include linear kernel, polynomial kernel, radial basis function (BRF), and sigmoid kernel (Haykin, 1999). Each of these kernel functions is constructed with multiple parameters, and how these parameters are set can influence the performance of a specific support vector machine (Yang, 2011). 
Urban area is defined as a spatial resource with specific segments for communication, residential, commercial, industrial, educational, and other purposes for sustained human habitation (Okpala-Okaka, 2011). Charles Chukwuma Soludo (professor of economics and former Governor of Central Bank of Nigeria) in his keynote address at the 2nd Anambra Economic Summit titled "Anambra 2030: Envisioning the African Dubai, Taiwan and Silicon Valley" notated that the robust data on the major urban trends and features of Anambra are absent or weak. According to him our major cities have no suitable recreational facility, open spaces, sewage and waste disposal system, not even walkways or flood disposal paths and thus are not planned for people to live a qualitative life, (Soludo, 2006).

One of the prime prerequisites for better use of land is data on the existing land use patterns and changes in landuse/landcover through time and if public agencies and private organizations are to know what is happening on the land, and to make sound plans for their own future action; then reliable data is imperative. However, this basic geospatial information is lacking in this study area. Physical observation by the researcher shows that the development of the city of Nnewi needs serious planning to avoid the danger looming around the city due to urbanization and industrialization of the area. The development of the city of Nnewi needs serious bottom-up planning rather than top-to-bottom planning approach in order to avoid any avoidable error looming around the city, like unplanned development, narrow roads/poor road network, poor traffic control, lack of open space and gardens among others which obviously are possible because of population growth, urbanization, and industrialization of the zone. From existing information stored in the 1964 topographical map of Nnewi, the city was just a rural area with scattered family settlement pattern, then, population was less and amenities were little or none in existence. But now, the reverse is the case, therefore, it is never too late to restructure the city for a sustainable urban development.

It is abundantly clear that when maps and master plan of an area are available, they will definitely guide in the urban development, especially as a working document for enforcing planning laws for both government and the private urban developers. Hence, map is very essential for geospatial location of features and for siting new development among numerous applications. It is also understandable that sustainable planning and development strategies cannot be properly implemented without mapping the existing features within an area. Therefore, landuse/landcover information depicting the natural and cultural features that will be mined from high resolution satellite imagery and classified using SVM classifiers which will serve as a base map for urban renewal and monitoring of the daily development going on in the city of Nnewi is a necessity.

\section{Study Area}

The study area for this research is Nnewi North Local Government Area of Anambra state, South-Eastern region Nigeria, (Fig. 1A), created in 1996 from old Nnewi Local Government Area, spans over 1,076 square miles $(2789 \mathrm{~km} 2)$, lying about $25 \mathrm{~km}$ south of Onitsha in Anambra state, (Amanze, Eze and Okoronkwo 2015), (Fig. 1B). It is located between latitudes $5^{\circ} 59^{\prime} 41.64 " \mathrm{~N}$ and $6^{\circ} 03^{\prime} 28.44^{\prime \prime} \mathrm{N}$ and longitudes $6^{\circ} 03^{\prime} 28.44^{\prime \prime} \mathrm{E}$ and $6^{\circ} 52^{\prime} 41.64^{\prime \prime} \mathrm{E}$ bounded in the north by Idemili South, South West by Ekwusigo, and South East by Nnewi South L.G.As of Anambra State (Fig. 1C). The study area is also known as Nnewi urban consisting of four quarters; Otolo, Umudim, Nnewichi and Uruagu (Fig 1C). The local government headquarters is located at Umudim; the famous Nkwo market is sited at Uruagu; the Nnamdi Azikiwe University Teaching hospital is situated at Nnewichi while Otolo ward houses most of the major industries in Nnewi urban area, (Obeta, 2015).

\subsection{Geomorphology of the area}

Topographically, Nnewi North is located on lower Niger plains and Mamu River plains. These plains and lowlands have great rolling topography, generally below $122 \mathrm{~m}$ above sea level. The Awka-Orlu uplands extend to this area, (Orajiaka, 1975). The altitude ranges from $105 \mathrm{~m}$ to $300 \mathrm{~m}$ above sea-level. The soil of the area is derived from the sedimentary rocks of middle cretaceous to lower tertiary age and of ferralitic type, (Jungerius, Badwen and Obihara 1964). Although it is rich in free iron, its low mineral reserve and deep porous red colour conveys an illusion of homogeneity of its properties across the area (Phil-Eze 2010, Obeta, 2015). 


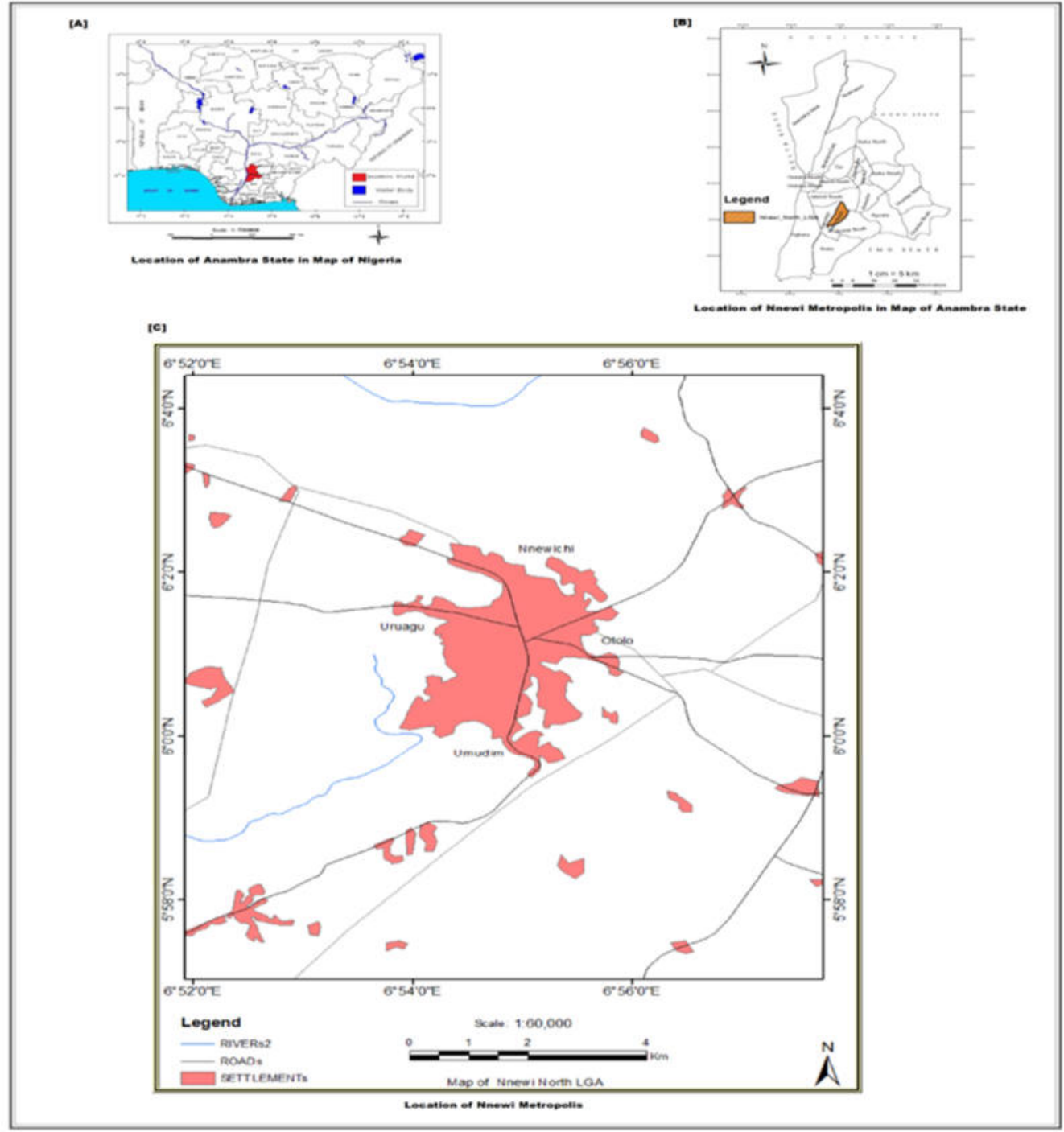

Figure 1: Location of the Study Area.

Figure 1A: Location of Anambra State in the map of Nigeria, Figure 1B, Location of Nnewi North LGA in the map of Anambra State and Figure 1C., the thematic map of study area depicting the four quarters of Nnewi North.

Source: (Ezeomedo, 2019).

\subsection{Geomorphology of the area}

The area witnesses two distinctive climatic changes in a year, the dry season and rainy season, with a maximum temperature of $34^{\circ} \mathrm{C}$ and minimum temperature of $24^{\circ} \mathrm{C}$. It has a topical climate influenced by two major trade winds, the warm moist south west trade winds during rainy season (April-October) and the northeast trade wind during dry and dust harmattan (November - march), (UN-Habitat, 2009). The city records highest rainfall around September. The rain occurs as violent downpour accompanied with thunderstorm and heavy flooding, (Orjiako and Igbokwe, 2009). Humidity of Nnewi North varies between $40 \%$ and $92 \%$. It is generally high during the early hours of the day heightens highest in July during the rainy season and lowest in January during harmattan (PhilEze, 2010). The study area falls within the tropical rainforest zone of West Africa, this vegetation however, degraded by over 30 years of infrastructural development, aggressive industrial and urbanization processes, (Orjiako and Igbokwe, 2009, Phil-Eze 2010). 


\subsection{The Socio-Economic Status of the area}

The traditional monarch of Nnewi is called the Igwe. The present Igwe is his Royal Highness Igwe Kenneth Orizu III, who presides over the affairs of Nnewi. He is been assisted by other three Obis of the other three villages. In Nnewi, Ofia-Olu festival is an annual event and all the four quarters observe it. It is a part of people's culture that is very clear to them and affords them an opportunity to relax and enjoy themselves at year's end. The festivals are usually very colourful and feature a lot of cultural masquerades and dancers (Ogbuagu, 2010). The population of Nnewi according to NPC (2006) was 79962 for male and 77607 for female totalling 157569. Since the annual growth rate of population in Nigeria is estimated at 3.2\%, the population of Nnewi was projected from 2006 to 2017 as 222,816, Ezeomedo (2019). The main occupation of the people of the study area is trading and farming. Most of the prime cash crops produced include; oil palm, raffia palm, groundnut, cotton, cocoa, rubber, maize etc. food crops such as yam, cassava, cocoyam, bread fruit, etc. Nnewi is home to many agro-allied, automobile and manufacturing industries (Amanze, Eze and Okoronkwo 2015, Anambra RHFA Report, 2013). Landuse within the area is not orderly and varies between residential, commercial, industrial and cultural types with each type dominating according to the perceived interest of the landowners, (Phil-Eze 2010).

Nnewi (popularly called the Japan of Africa) is said to be the second largest economic hub of Anambra state after Onitsha and one of the largest in West Africa, (Brautigam 1997, Orji and Obasi, 2012). Together with Aba and Onitsha, Nnewi forms part of the eastern Nigeria's "New industrial axis". Industrialization of the town began around 1970 when Nnewi motor parts traders began marketing their own brand name products instead of the reproductions of "original" parts (Onwutalobi, 2009). It has institutions like: Nnamdi Azikiwe University teaching hospital, Nnewi; College of Health Sciences Nnewi, Odumegwu Ojukwu Polytechnic, Ezinifite, Nnewi-South among others, (Anigbogu, Onwuteaka, Edoko and Okoli 2014).

\section{Materials and Methods}

\subsection{Data Used}

The Administrative map of Nigeria, Anambra State and Nnewi North LGA was obtained from office of the Surveyor General of the Federation (SGoF) and was modified by the author in the Remote Sensing and GIS Laboratory, Department of Environment Management, Chukwuemeka Odumegwu Ojukwu University, (2017). Topographical map of study area (published in 1964) was obtained from the Ministry of Surveys and Town Planning, Awka. While High Resolution Satellite image of Nnewi North LGA (GeoEye-1 Image of 2016) was obtained from DigitalGlobe online in ECW format (Enhanced Compressed Wavelet; a proprietary data format developed by Earth Resource Mapping that is primarily intended for aerial imagery).

\subsection{Data Processing}

The research methodology was based on remotely sensed data processing using SVM algorithm application to produce and visualize the land information of area of study. Fig.2. Data requirement includes hardware and software requirement, Data acquisition, modelling and processing was carried out to obtain the desired results.

The initial preparation for the processing of any remotely sensed image data is done under pre-processing. This involves reading the user requirements and the input data and storing these information \& data for further processing in the appropriate format under a project area. The input data was radiometrically and geometrically corrected by GeoEye image cooperation. Data georeferencing and transformation was also carried by vendors. The study used Environment for visualizing images (ENVI) software, version 5.1 for image processing, image enhancement, Filtering and masking and Image classification. Meanwhile, ArcGIS 10.2 was employed for production of thematic maps and Microsoft Excel was employed for data analysis and results presentation.

The following processing procedures were carried out (Figure 2):

i. Image enhancement

ii. Image Sub-setting

iii. Extraction of Regions of Interests (ROIs)

iv. Supervised classification using SVM

v. Post-processing Accuracy Assessment

vi. Preparation of maps 


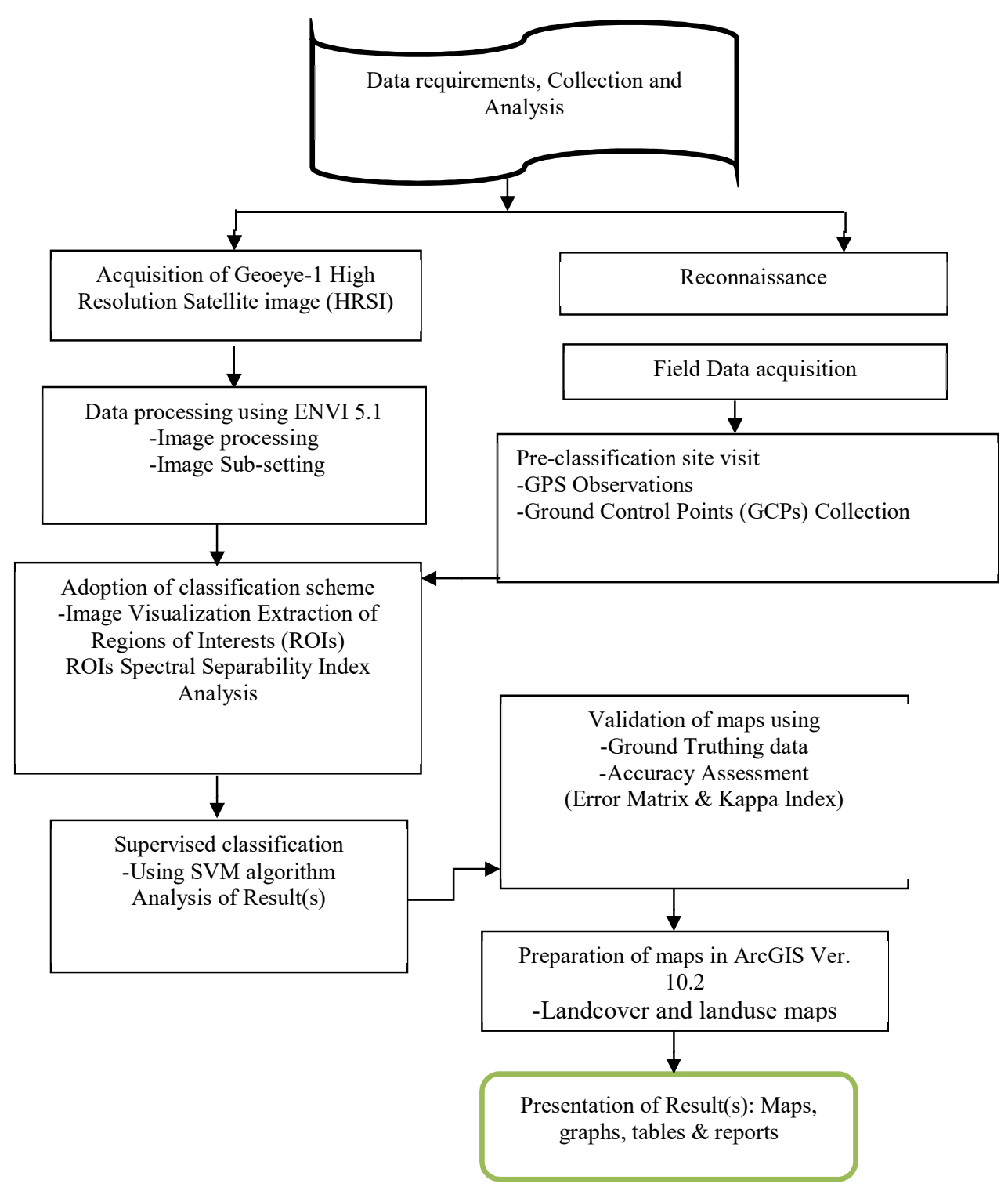

Figure 2: Flowchart of Methodology

First is downloading and saving the image data in a computer, link the image to a folder and Launch the ENVI. To process images using ENVI+IDL (Interactive Data Language) it starts by launching the ENVI Version 5.1, IDL is a high-level programming language that contains an extensive library of image processing and analysis routines. With IDL, you can quickly visualized image data and begin investigating the best way to extract useful information, (Fig.3 and 4). 


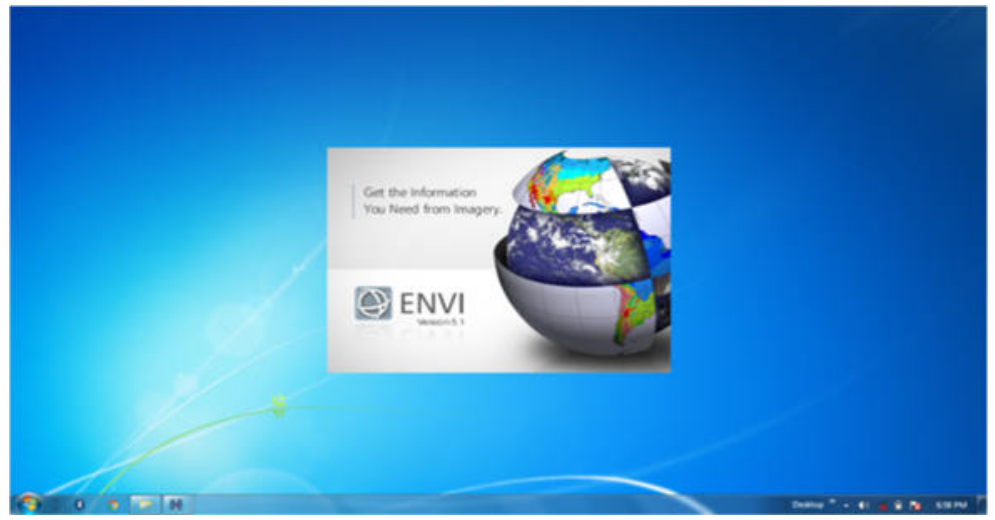

Figure 3: ENVI 5.1 window + IDL 8.3 algorithm after it was launched

Source: Exelis Visual Information Solutions, Inc (2013). ENVI 5.1 Software + IDL Version 8.3. Screen shot by the author.

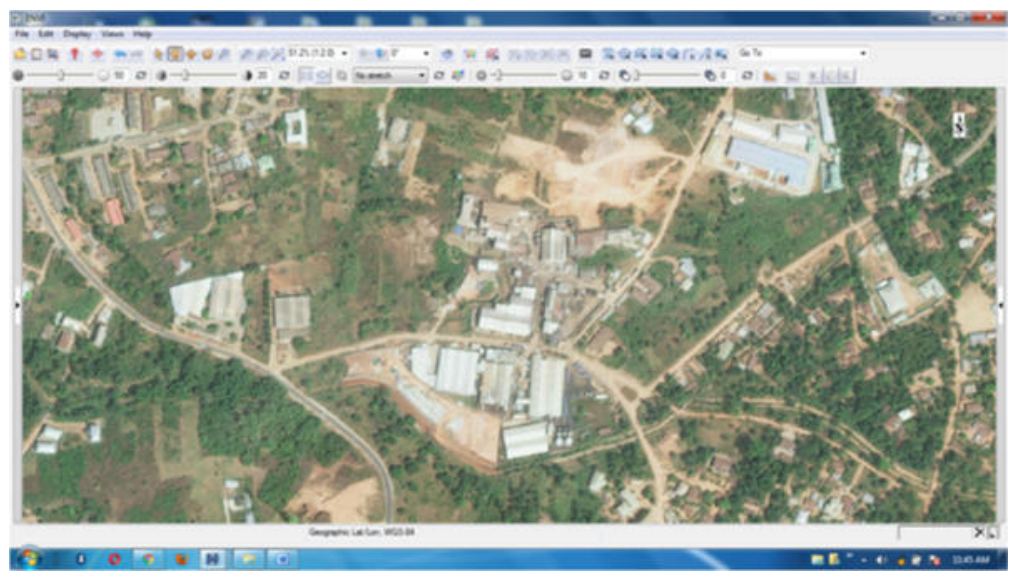

Figure 4: Sample of visualized raster image

The Visualized raster image is showing part of Umudim Nnewi Industrial zone in ENVI 5.1 window + IDL 8.3 system, immediately after image enhancement (Figure 4).

\subsection{Image Sub-setting}

Image subsetting was carried out using the new shape file of Nnewi Local Government Area, Fig. 5B. Remember more States and Local government areas were created in Nigeria in 1967, 1976, 1987, 1991 and 1996 respectively and subsequently some of our administrative boundary were not updated and one of them is this map of old Nnewi Local Government Area map Fig. 5A. 


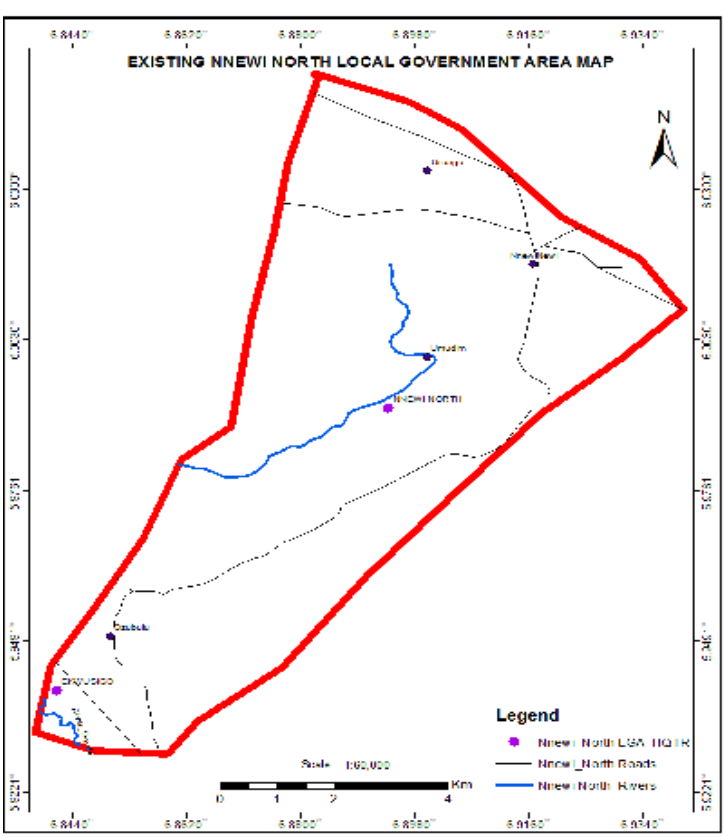

Figure 5A: Old Shape File

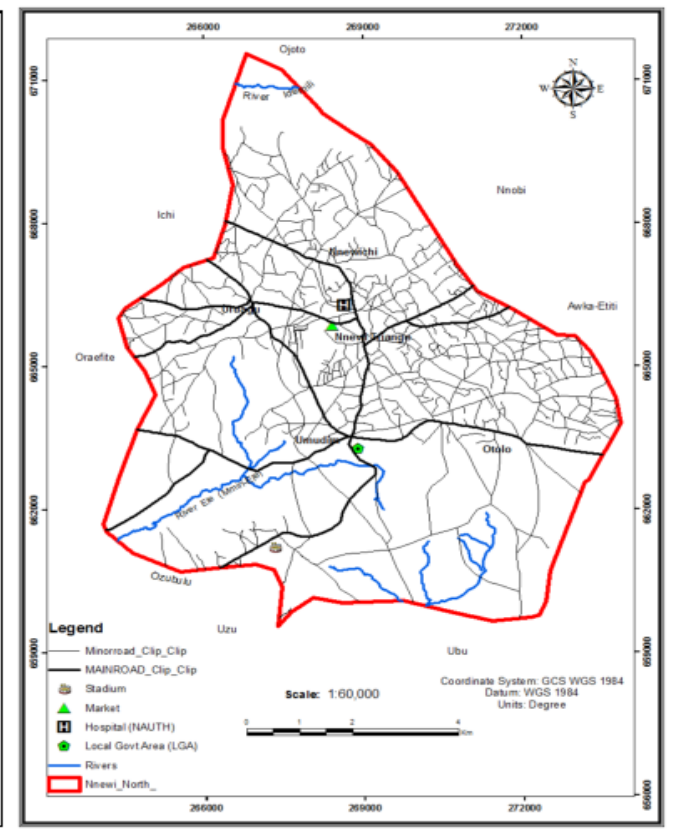

Figure 5B: New Shape File

Figure 5: Old and New Shape File Nnewi-North.

Figure 5A, old Nnewi Local Government Area map comprising of some part of Ekwusigo LGA. This Shows that the Nnewi-North LGA map is not updated. Figure 5B: The up-to-date shape was used for image subsetting, image classification and map production.

\subsection{Extraction of Regions of Interests (ROIs)}

ROIs are usually image classification scheme containing information of classes of interest such as built up area, farm lands, vegetation areas, water bodies, and open/bare surface among other features of interest. Supervised classification requires that the analyst be familiar with the area of interest and needs to know where to find these classes of interest in the area covered by the satellite image. The "Extraction of Regions of Interests (ROIs)" was careful carried out by creating ROIs from High Resolution Satellite Image (HRSI) geometry using ROIs tool. From a processing standpoint, ROIs are pixel addresses with associated data. With the assistance of the ROI editor/ toolbar, you can easily create training samples to represent the classes you want to extract. For the computer to be properly guided on the classification process the selected ROIs are assigned with name, codes and colour. The five classes of interest were adopted which includes the built-up areas; vegetation, wetlands/water bodies, buildings/pavement, open/bare surfaces and farm lands were extracted and saved in right format and used for further analysis, see example of Regions of Interests (ROIs) in Figure 6. 


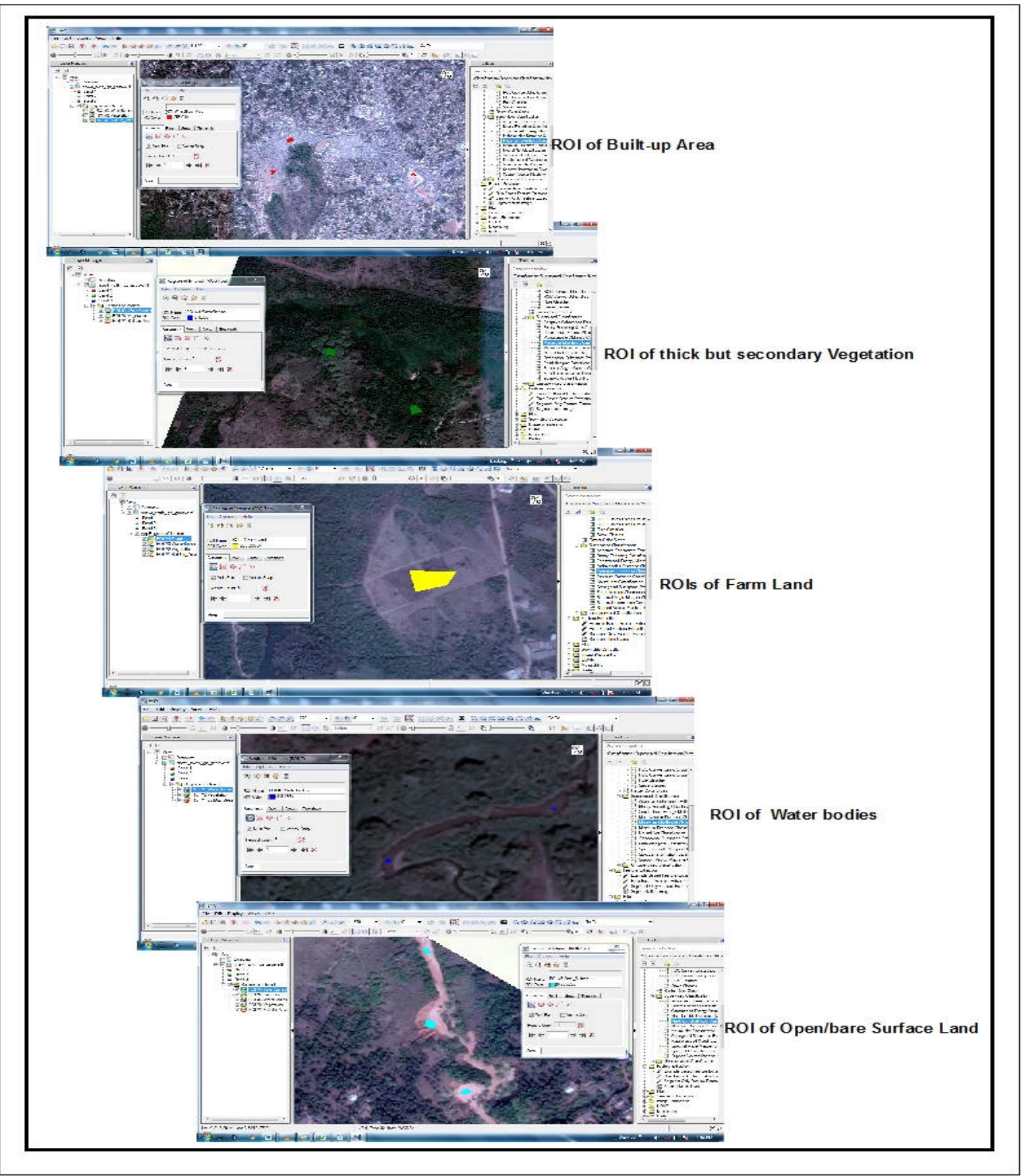

Figure 6: ROI of five adopted classes.

It shows the ROI tool in action during extraction of ROI classes. the analyst used $\# 1$ to $\# 5$ as the code for the five classes of interest and various colours that can distinguish one class from another and the colour selected were close to the natural colour of the features of interest. 


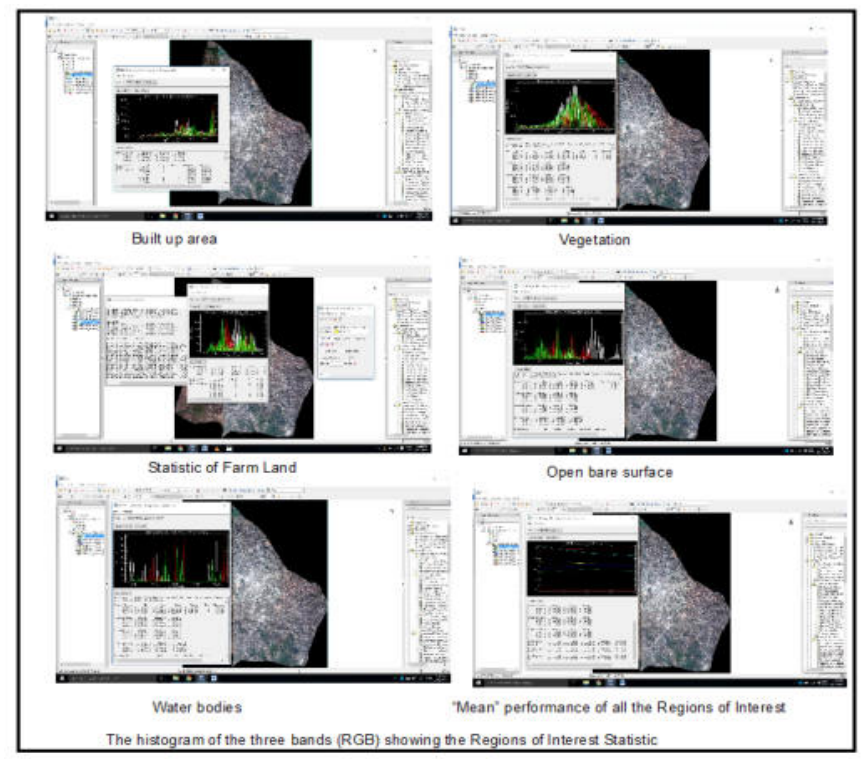

Figure 7: Regions of Interest Statistic Analysis

3.4.1. The spectral separability index analysis

The research used the ROI Separability tool to compute the spectral separability between selected ROI pairs for a given input file. In this case, both the Jeffries-Matusita and Transformed Divergence separability measures were testified (Figure 8). The values range from 0 to 2.0 and indicate how well the selected ROI pairs are statistically separate. Values greater than 1.9 indicate that the ROI pairs have good separability. For ROI pairs with lower separability values, you should attempt to improve the separability by editing the ROIs or by selecting new ROIs. For ROI pairs with very low separability values (less than 1), you might want to combine them into a single ROI. For good classification results using these ROIs, the groups of pixels for the different ROIs should be separate from each other and should not overlap.

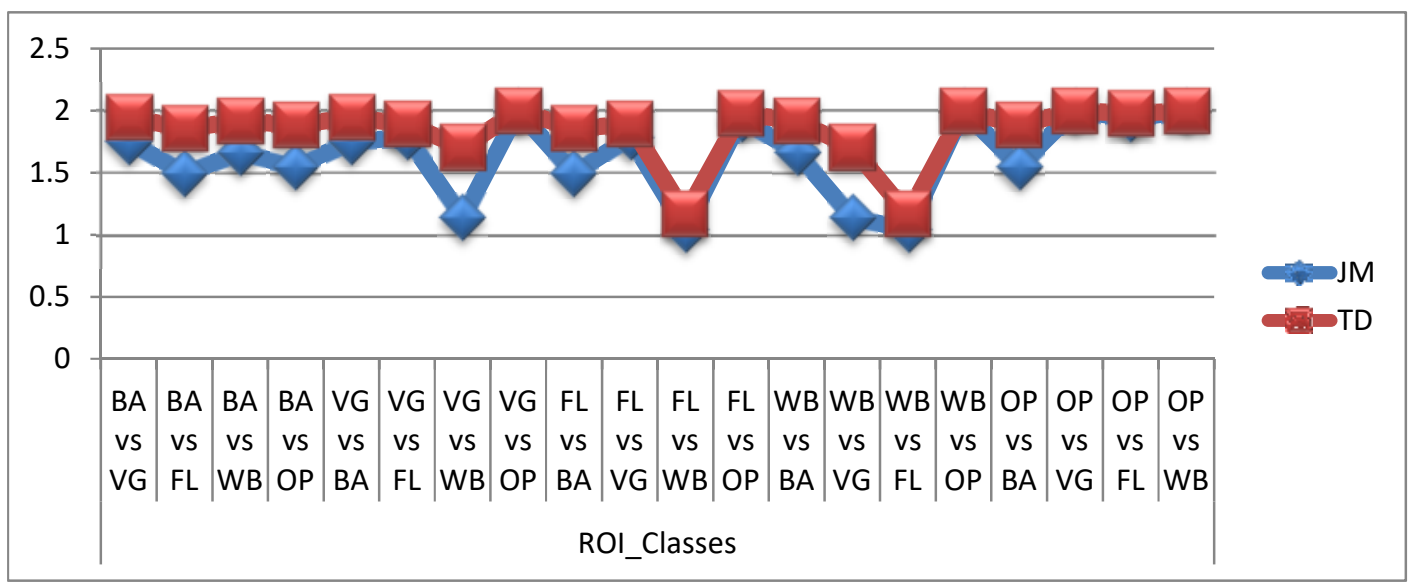

Figure 8: Graph of the Ground Truth ROIs pair separation (Least to most)

Figure 8, Graph of the Ground Truth ROIs pair separation (Least to most) was calculated using Jeffries-Matusita and Transformed Divergence separability of the Ground Truth ROIs. Where, JM means Jeffries-Matusita, while $\mathrm{TD}$ is Transformed Divergence. Similarly, BA= Built-up Area, VG = Vegetation, FL= Farm Land, WB = Water bodies, $\mathrm{OP}=\mathrm{Open} /$ bare surfaces and While the masked area was not used in computation because the value is zero. The analysis was done such that one ROI (Class) was run against another and vice-versa to ascertain their separability.

\subsection{Image Classification Process}

Image classification refers to the computer-assisted interpretation of remotely sensed images. Environment for visualizing images, ENVI software version 5.1 was used for GeoEye-1 image supervised classification. Object- 
based processing was adopted which are techniques that classify a set of input objects rather than classifying pixels individually. There are various classification approaches that have been developed and widely used to produce land cover maps over the years. They includes, supervised to unsupervised; parametric to non- parametric to nonmetric, or hard and soft (fuzzy) classification, or per-pixel, sub-pixel, and among others but SVM supervised Classifier was adopted in this research.

In the case of supervised classification, the software system delineates specific landcover types based on statistical characterization data drawn from known examples in the image (known as Region of Interests (ROIs) in ENVI) but requires that the operator be familiar with the area of interest in the area covered by the image. There are several techniques for making these decisions, called classifiers. Most Image Processing software will offer several, based on varying decision rules. SVMC of ENVI window was tested, The image classification was done using Radial Basis Function (BRF) default kernel in ENVI 5.1 Figure 9 shows SVMC at its 100\% Classification Process.

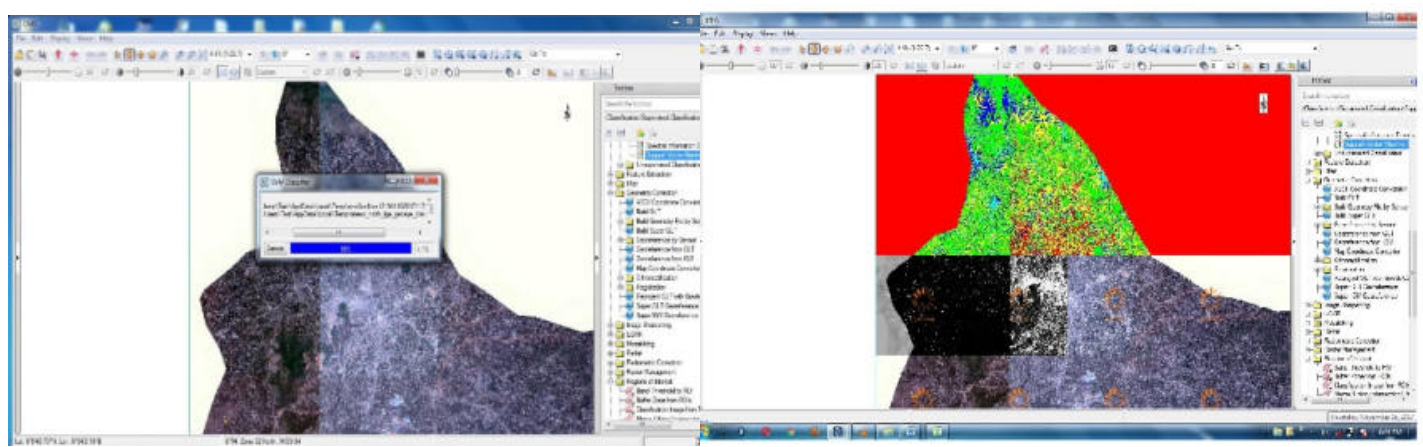

Figure 9: SVMC at its 100\% Classification Process.

After Image classification is post-processing, including ground truthing/field verification and Computation of the error matrix to assess accuracy of the job, the next thing is to accept the result of image classification if it is satisfactory, otherwise you may reject the result and retrain the image for better performance.

\subsection{Accuracy assessment}

The final classes must be assessed to ensure it is within permissible accuracy. This is done by generating confusion matrix and calculating derived errors and their accuracies. Also several sites were visited (ground truthing) in the study area with respect to the adopted classes of land use and land cover. Coordinates of the sites were also taken. Reference data collected through the process of "ground truthing", determination of class types at specific locations and Compare reference to classified map. The Trained ROIs/ Ground Truth ROIs were created and were used to produce ground truth image that used for confusion matrix (contingency matrix) analysis.

\subsubsection{Overall accuracy}

This is computed by dividing the total correct number of pixels (i.e. summation of the diagonal) to the total number of pixels in the matrix (grand total). The overall is $98.0692 \%$.

3.6.2. Producer's accuracy

This refers to the probability of a reference pixel being classified correctly. It is also known as omission error because it only gives the proportion of the correctly classified pixels. It is obtained by dividing the number of correctly classified pixels in the category by the total number of pixels of the category in the reference data. The overall result of the producer's accuracy ranges from $91.10 \%$ to $100 \%$

\subsubsection{User's accuracy}

This assesses the probability that the pixels in the classified map or image represent that class on the ground, Congalton (1991). It is obtained by dividing the total number of correctly classified pixels in the category by the total number of pixels on the classified image. User's accuracy of individual classes ranges from $89.76 \%$ to 100 , vegetation and water bodies presented low accuracy for the land cover map. The vegetation and water bodies were, to some extent, misclassified as Built-up areas, vegetation and farm lands respectively. 


\subsubsection{Kappa coefficient}

The Kappa coefficient was calculated using the formula given in Congalton (1991), Pradhan, Sharaf and Abubakar, (2013). Error Matrix and Kappa Coefficient results revealed Kappa Coefficient $=0.97$ These Kappa results are considered to be a good result because an interpretation for SVMC is between (0.81-1.00) which is almost perfect agreement.

3.7. Results from the image classification

The study realised that High Resolution Remote Sensing imagery and ENVI Software is robust tool for automatic image identification and classification but requires subjective manipulation of input parameters.

\subsubsection{Built-Up Areas}

The Built-up Areas is $13.52 \%$, the percentage of built-up area shows that Nnewi-North LGA still has available land for good developmental planning, that is, since out of $100 \%$ its only $13.6 \%$ has been developed. Hence, urban renewal can recover some percentage out of $13.6 \%$ when the government is willing to plan for the future. It must start with urban renewal, proper zoning and coordination to have an adorable smart city that will attract the foreign investors to the city. Since, there is no other option than to plan for the sustainable development of Nnewi, (Table $1)$.

\subsubsection{Vegetation}

The result of SVMC is $24.23 \%$ of Vegetation, This can be as a result of upsurge demand for land for Residential, commercial services, industrial complexes, transportation among other infrastructures, (Table 1).

\subsubsection{Water Bodies}

The $22.05 \%$ of Water bodies include rivers, streams, lakes, etc. Artificial lakes were visualised around Umudim and Otolo, while other water bodies includes Idemili River around Nnewi-ichi border with Ojoto, Ele River (Mmiri-Ele) within the Uruagu/ Umudim flowing East-west of the City and Ubu River flowing South-Eastern part of the Umudim-Otolo Nnewi within the border area of Ubu-Osigbu, Ukpor, (Table 1).

\subsubsection{Farm Land}

This includes, gardens, field crops, Horticulture, orchards, improve pasture, ploughed fields and fallow land as captured and trained by the analyst. Farm lands is equal to 39.40, Farm lands are noticeable around urban fringes of city within all the four quarters of Nnewi with little or no settlement around them, (Table 1).

\subsubsection{Open/Barren Land}

This class includes excavation sites, barren lands, erosion sites, playground and unpaved roads. This class was accurately classified because proportion of their Errors of Omission and that of Commission were less. The percentage of open/barren land is $0.81 \%$, (Table 1 ).

Table 1: Summary result of landuse/landcover of the study area

\begin{tabular}{|lllllll|}
$\mathbf{S} / \mathbf{N}$ & Classes ( ROIs) & $\begin{array}{l}\text { Cod } \\
\mathrm{e}\end{array}$ & Colour Used & $\begin{array}{l}\text { Points } \\
\text { (PIXELS) }\end{array}$ & $\begin{array}{l}\text { Percentage } \\
\%\end{array}$ & Area $\left(\mathrm{km}^{2}\right)$ \\
$\mathbf{1}$ & Built-Up Area & $\# 1$ & Mars Red & $26,687,844$ & 13.52 & 929.00 \\
\hline $\mathbf{2}$ & Vegetation & $\# 2$ & Leaf Green & $47,788,163$ & 24.23 & $1,663.51$ \\
\hline $\mathbf{3}$ & Water Bodies & $\# 3$ & Lapis Lazuli & $43,514,121$ & 22.05 & $1,514.73$ \\
\hline $\mathbf{4}$ & Farm Land & $\# 4$ & Solar Yellow & $77,742,135$ & 39.40 & $2,706.20$ \\
\hline $\mathbf{5}$ & Open/Bare & $\# 5$ & Indicolite Green & $1,602,180$ & 0.80 & 55.77 \\
\hline & & & Total: & $197,334,443$ & 100.00 & $6,869.21$ \\
\hline
\end{tabular}




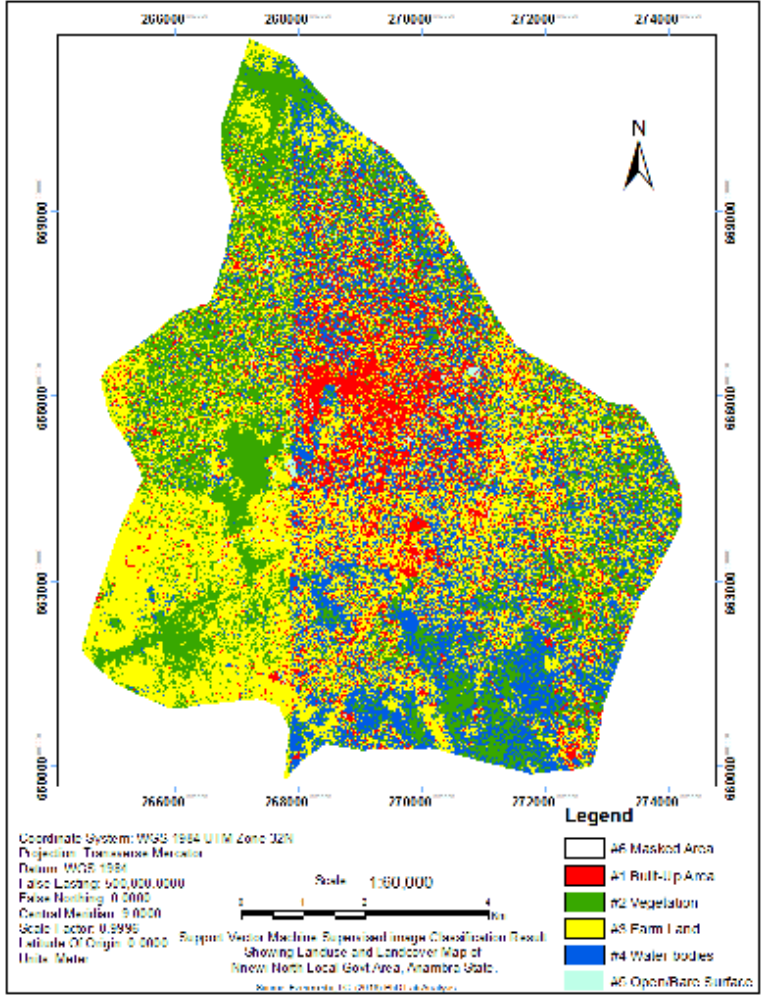

Figure 10A

Figure 10: The Classification Results.

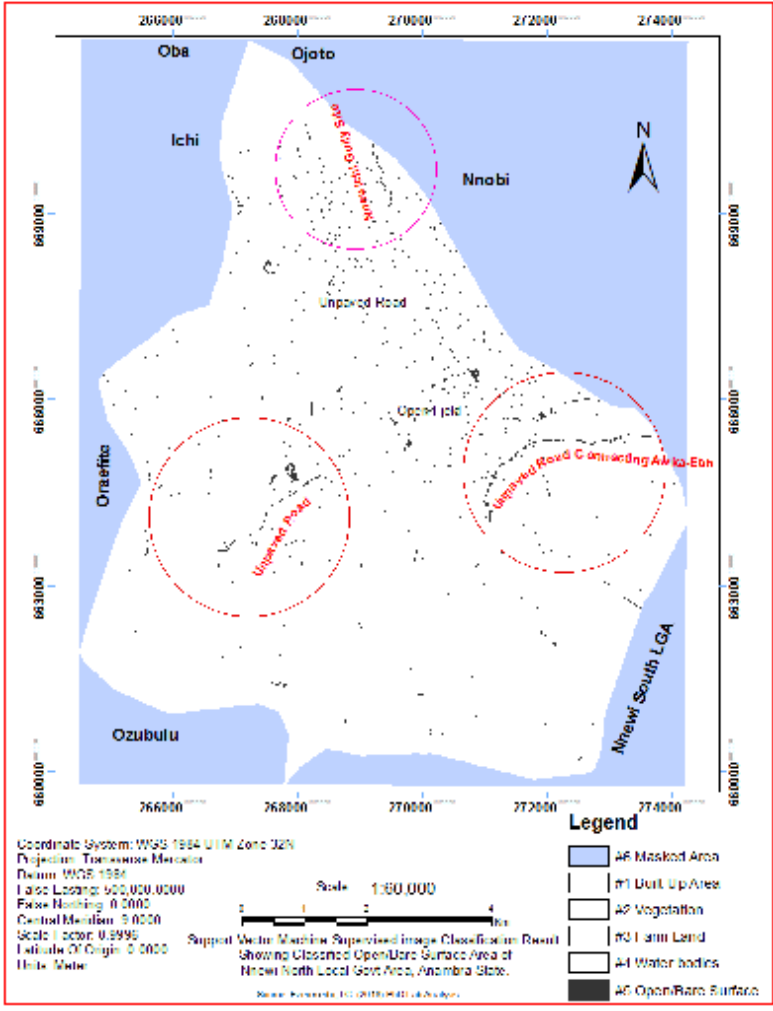

Figure 10B

Figure 10A: landuse/landcover map produced, Figure 10B: Classified Open/bare Surface, highlighted in red circle indicating how well unpaved roads, bare surfaces and erosion site were classified using ENVI.

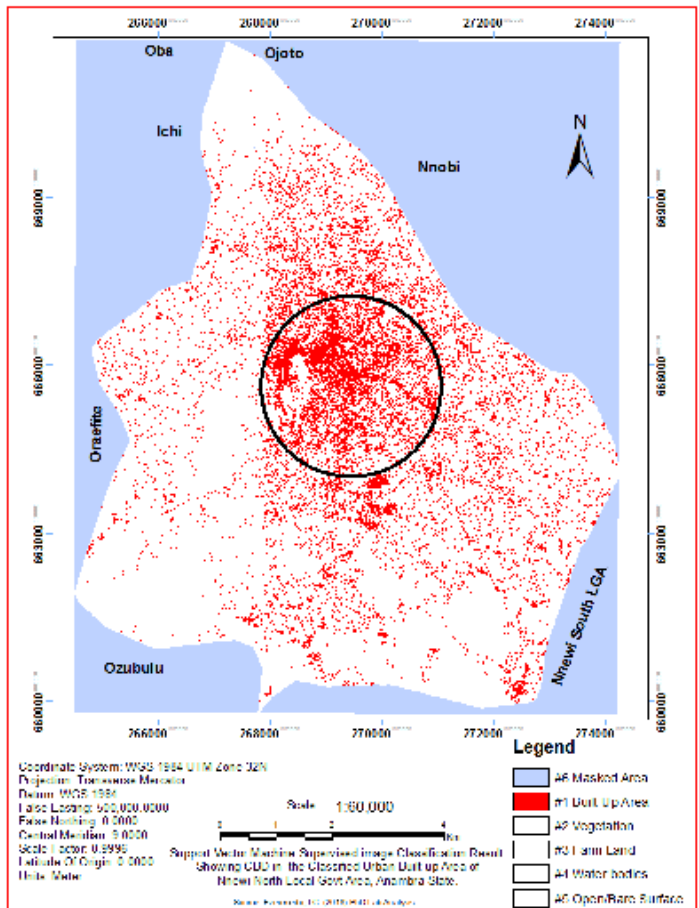

Figure 11A

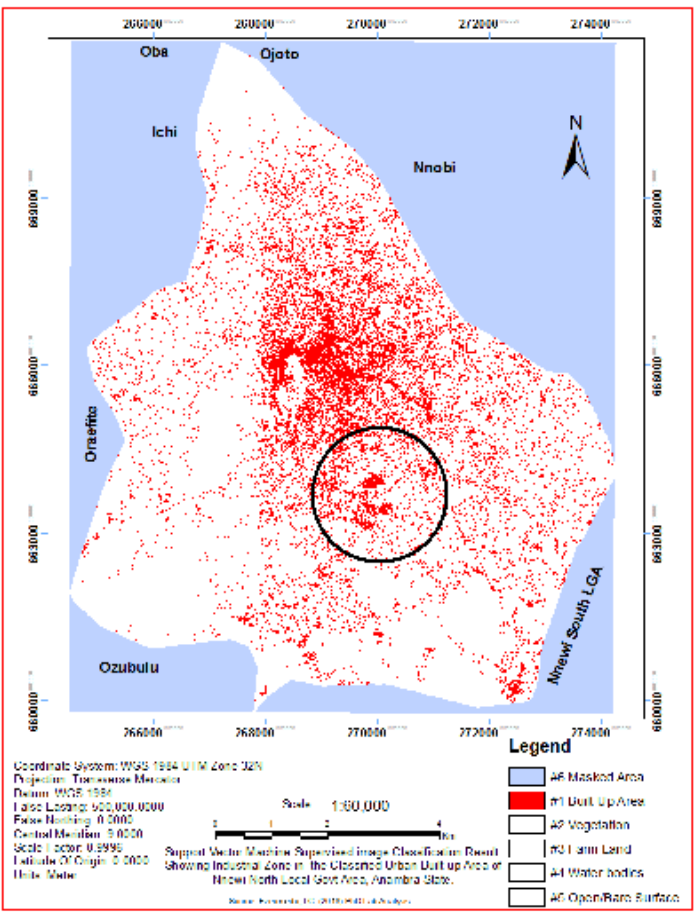

Figure 11B

Figure 11: Classified Built-Up Area of Nnewi-North LGA 
Figure 11 A: Central Business Districts (CBD) the popular 'Nkwo Nnewi' encircled with black ink. The result shows a compacted Settlement pattern. Figure 11B: Industrial Zone mainly at Umudim Industrial Estate encircled with black ink. The presence of an industrial estate and a big market "Nkwo Nnewi' is believed to have brought the development to Nnewi and therefore attracted huge population to the city.

\subsection{Preparation of maps}

\subsubsection{Creation of Layer in ArcGIS 10.2}

ArcGIS 10.1 was employed for producing thematic maps. Microsoft Excel was employed for data analysis and results presentation. So, at this stage, the result of classified image in ENVI software was exported to ArcGIS 10.2 as vector layer for cartographical analysis and design. ENVI can easily convert the raster result to vector automatically just clicking at the icon (conversion to vector). Thereafter, the result of image classification was used for creating physical vector layers, that is, the polygon, line or point features layers of objects mapped. Thus, the following layers was created in Arc Catalog in a personal Geodatabase, The "National Town Planning Standard Urban Planning Code" was applied for instance, Commercial Area (Navy Blue), Industrial Area (Pink), Educational (Schools), Institutional/Administrative (Red), Residential Area or Mixed Landuse (Light Yellow), Public Utilities (Brown), Recreational Area which includes Green Spaces, Open Space \& Parks (Light Green), Areas Liable to Flooding (Light Blue), Agricultural area (Green), other are Circulation/Roads (Black), Ifeanyi Uba Stadium, Local Government Area (LGA), Market, Hospital (NAUTH) and Heritage site among others were clearly represented in figure 12. Figure 12 is the landuse and landcover of Nnewi North captured in GeoEye-1 2016 Satellite image.

\section{Conclusion and Recommendations}

This research used subset of the satellite imagery covering Nnewi-North LGA in producing a baseline landuse and landcover map of the study area using the correct shape file of Nnewi-North, to represent the precise land extent after Ekwusigo L.G.A was carved out of Nnewi-North in 1996 by General Sani Abacha (GCFR). Hence, the research objective of producing the land use and landcover map of Nnewi-North L.G.A, that will serves as a base map for improved land-use planning and monitoring, for a variety of end-users was achieved with an additional advantage of using the most current boundary line of Nnewi-North L.G.A. The results of the classified GeoEye-1 2016 Satellite image of Nnewi North using Support Vector Machine (SVM) algorithm incorporated in ENVI software revealed enormous evidence about the present percentages and size of the built-up area, Vegetation cover, Water bodies, Farm land and Open/bare surface of the classes of interest classified with respect to this current boundary. The result showed that only built-up areas and open/bare surfaces were well classified without conflicting with the spectral signatures of other urban features and this confirmed that SVMC in ENVI software is robust in detecting urban infrastructural developments. This study is hereby advocating for the integration of developmental activities in Nnewi North local government area into the basemap of the area for proper siting of new features at the right places, proper monitoring and for urban sustainability. 


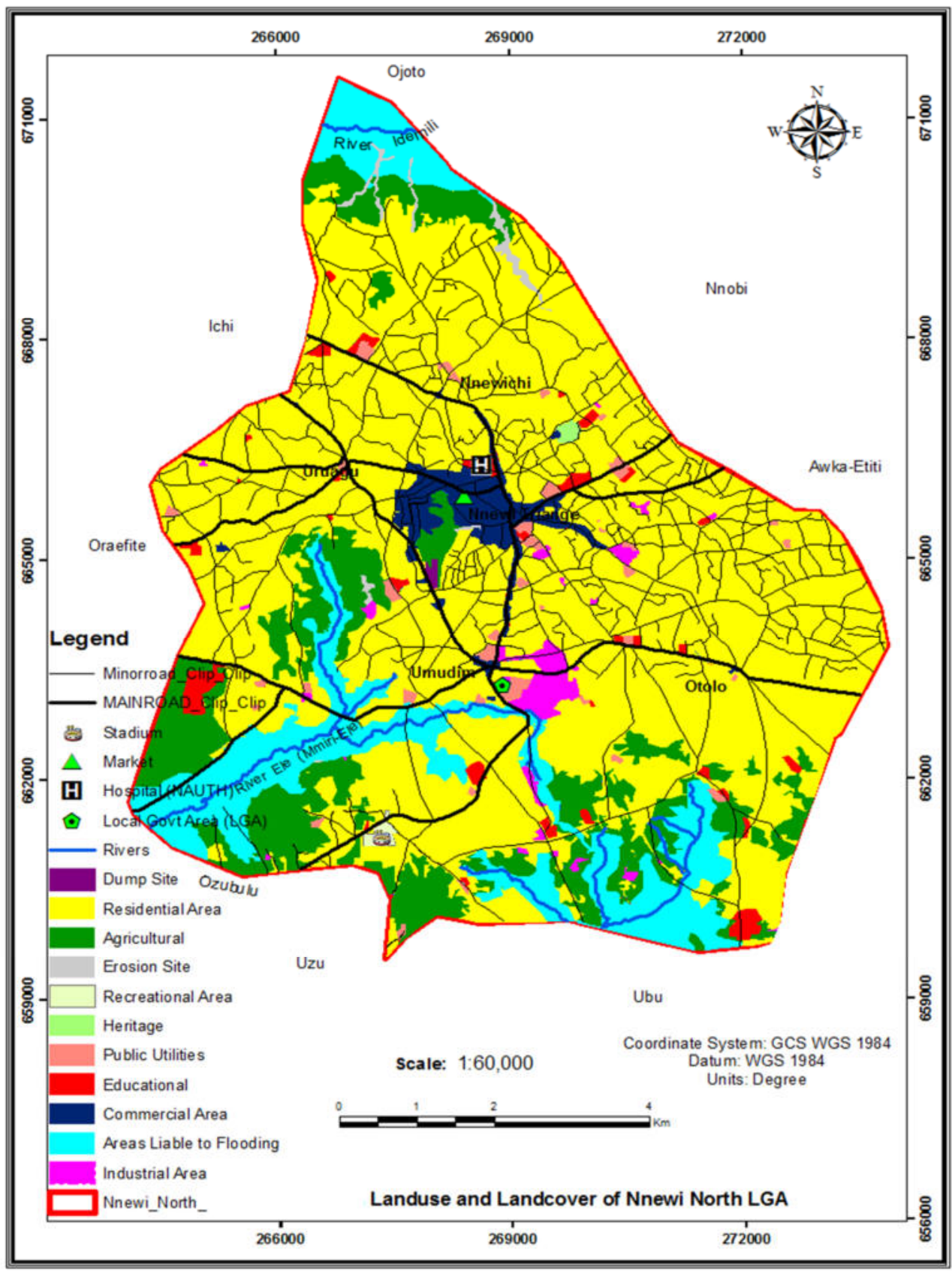

Figure 12: Physical vector map of Nnewi North LGA using the planner's concept of urban delineation in Esri ArcGIS 10.2.

\section{References}

Amanze J.O, Ezeh C.I and Okoronkwo, M.O (2015). Pattern of Income Diversification strategies among Rural Farmers in Nnewi North Local Government Area of Anambra. Journal of Economics and Sustainable Development Vol. 6, No.5.

Anambra State Ministry of Health and FHI 360. (2013). Anambra State Wide Rapid Health Facility Assessment, Nigeria: Anambra State Ministry of Health and FHI 360.

Anigbogu, T.U, Onwuteaka, C.I, Edoko, T.D, Okoli, M.I (2014). Roles of Small and Medium Scale Enterprises in Community Development: Evidence from Anambra South Senatorial Zone, Anambra State. International Journal 
of Academic Research in Business and Social Sciences, Vol. 4, No. 8.

Brautigam, D. (1997). Substituting for the State: Institutions and Industrial Development in Eastern Nigeria. World Development Vol. 25, No. 7 Pp. 1063-1080.

Ezeomedo, I.C., (2019) Automatic Identification and Mapping of Urban Features of Nnewi using High Resolution Satellite Image and Support Vector Machine Classifier. Unpublished Ph.D. Dissertation Submitted to the Department of Surveying and Geoinformatics, Nnamdi Azikiwe University, Awka, Nigeria.

Haykin, S. (1999). Neural Networks: A Comprehensive Foundations, 2ed. Upper Saddle River: Prentice Hall.

Jensen, T. R., (2007). Remote Sensing of the Environment: an Earth Resource Perspective. Pearson Prentice Hall, United States of America. 2nd Ed. Chapter one.

Jungerius, P.O, Badwen MG, Obihara C.H (1964). “Anambra-Do river area” Soil Survey Memoir, No.1. Govt. Printer, Enugu. Nig.

Kramer J. H., (2002). Observation of the earth and its environment: Survey of missions and sensors (4th Ed). Berlin: Springer.

Levin N. (1999). Fundamentals of remote sensing. A book compiled using Internet resources, articles and personal knowledge, 225 pages.

National Population Commission (2007): 2006 Population Census of the Federal Republic of Nigeria Official Gazzette. Vol. 94, No. 24, Lagos.

Obeta, M.C. (2015). Industrial Water Supply in Nnewi Urban Area of Anambra State, South Eastern Nigeria. Journal of Geography, Environment and Earth Science International, 2(1): 12-23.

Ogbuagu, C.N, Okoli, U.J, Oguoma V.M, Ogbuagu E.N. (2010). Orphans and Vulnerable Children Affected by Sexual Violence and HIV/AIDS in two Local Government Areas in Anambra State, Southeastern Nigeria. American-Eurasian Journal of Scientific Research 5(1):05-11.

Ojiako, J.C. and Igbokwe, J.I. (2009). Application of Remote Sensing and Multimedia Geographic Information System (GIS) in the Administration of Socio-Economic Activities in Nnewi Urban Area of Anambra State, Nigeria. Environmental Research Journal, Volume 3; Issue 2, Pp 60-67.

Okpala-Okaka, C., (2011). The Making of Urban Towns: A Comparison of the U.S and Nigerian Experiences. Journal of Environmental Management and Safety, Vol 2. (1)75 - 82.

Onwutalobi, C.A (2009). History of Otolo Nnewi. http://www.codewit.com/africa/1235-history-of-otolo-nnewiby-anthony-claret-onwutalobi. Available online (Retrieved 10/23/2014).

Orajiaka, S. O. (1975). 'Geology' in Ofomata G.E.K. (ed.) Nigeria in Maps: Eastern States: Ethiope Publishing House, Benin City.

Phil-Eze, P.O (2010). Variability of Soil Properties related to Vegetation Cover in Tropical Rainforest Landscape. Journal of Geography and Regional Planning. Vol.3 (7), pp. 177-184.

Pradhan, B; Sharif, A; and Abubakar, A. (2013). Monitoring and predicting landuse change in Tripoli metropolitan city using cellular automata models in geographic information system. A paper presented at a seminar organized at the University of Cairo, Egypt.

Sabino (2005). Fundamentals of remote sensing. Canadian Center for Remote Sensing, pp. 148 \& 161.

Shi Dee and Yang Xiaojun, (2012). Support Vector Machines for Landscape Mapping from Remote Sensor Imagery. Proceedings-AutoCarto 2012 - Columbus, Ohio, USA - September 16-18, 2012.

Soludo C.C., (2006). Anambra 2030: Envisioning the African Dubai, Taiwan and Silicon Valley. A keynote Address presented at the 2nd Anambra State Economic Summit at Parktonia Hotel, Awka May 25- 26, 2006.

UN-HABITAT. (2009). Structure Plan for Anambra State. Nairobi, Kenya: United Nations Human Settlements Programme Publishers.

Vapnik Vladimir N. (1995). The Nature of Statistical Learning Theory. Springer, Berlin Heidelberg New York. Yang, Xiaojun (2011), Parameterizing Support Vector Machines for Land Cover Classification, American Society Photogrammetric Engineering \& Remote Sensing, Vol. 77; No. 1, pp. 27-37. 